\begin{tabular}{|c|c|c|c|c|c|}
\hline Laboratory features & Acute & Subacute & Chronic tophaceous & Is Well controlled & $p$-value \\
\hline Uric acid & $7.22 \pm 2.07$ & $6.77 \pm 2.40$ & $6.94 \pm 2.20$ & $7.24 \pm 1.65$ & 0.780 \\
\hline ESR & $36.36 \pm 32.52$ & $18.87 \pm 18.98$ & $16.85 \pm 18.30$ & $8.29 \pm 7.67$ & $0.000^{m+n}$ \\
\hline CRP & $1.45 \pm 2.31$ & $0.45 \pm 1.12$ & $1.33 \pm 4.58$ & $0.12 \pm 0.08$ & $0.008^{m+1}$ \\
\hline Lipid profiles & . & . & o & ? & . \\
\hline Total cholesterol & $193.9 \pm 46.06$ & $208.39 \pm 47.77$ & $185.21 \pm 49.08$ & $163.14 \pm 44.93$ & $0.042^{t}$ \\
\hline HDL & $46.10 \pm 11.96$ & $43.28 \pm 9.51$ & $43.58 \pm 12.98$ & $42.57 \pm 8.76$ & 0.539 \\
\hline Triglyceride & $216.85 \pm 171.69$ & $221.55 \pm 117.9$ & $207.05 \pm 108.78$ & $180.57 \pm 125.70$ & 0.645 \\
\hline LDL & $126.81 \pm 55.04$ & $126.05 \pm 41.27$ & $119.98 \pm 38.95$ & $111.4 \pm 25.68$ & 0.825 \\
\hline Oxidized LDL & $785.38 \pm 369.14$ & $775.5 \pm 272.80$ & $653.23 \pm 430.99$ & $366 \pm 173.43$ & $0.001^{+t+\infty}$ \\
\hline
\end{tabular}

Conclusion: The levels of oxLDL in gout patients were significantly different according to inflammatory status. The oxLDL may be associated with inflammation process in gout patients.

Disclosure of Interests: None declared

DOI: 10.1136/annrheumdis-2019-eular.7113

\section{AB0878 CARDIOVASCULAR GOUT}

Eleanora Mikhnevich ${ }^{1}$, Tatiana Pavlovich ${ }^{2} .{ }^{1}$ Belarusian State Medical University, Internal Medecine, Rheumatology, Minsk, Belarus; ${ }^{2}$ Belarusian State Medical University, Internal Medecine, Minsk, Belarus

Background: Gout is characterized by clinical heterogeneity and associated with multicomorbidity. In clinical practice, we can highlight a group of patients suffering from cardiovascular diseases (CVD) and requiring constant medication, in which the gout joins later.

Objectives: To study the group of patients with gout developing on the basis of pre-existing CVD at the gout onset.

Methods: 240 patients from our Center database with confirmed gout were included in our study. Comorbidities were registered before the gout onset, at its appearance. The study group consisted of 140 patients with CVD: hypertension with duration for 5 years and treated by medication, $\mathrm{CHD}$, atrial fibrillation, CHF and stroke. The comparison group consisted of patients with gout, but without CVD ( $n=100)$.

Results: Among patients with pre-existing CVD, the gout debuted later, at the age of $60(55-65)$ years ( $p 0.001)$. The most frequent comorbidity was $\mathrm{HTN}-83.6 \%(\mathrm{n}=117)(\mathrm{OR}=7.63 ; 95 \% \mathrm{Cl} 5.33-10.93 ; \chi 2=48.9, \mathrm{p}$ 0.001). Diabetes mellitus $(\mathrm{OR}=4.47 ; 95 \% \mathrm{Cl} 3.65-5.48 ; \mathrm{F}=0.035, \mathrm{p}=$ 0.005 ) also dominated in this group. At the same time, BMl $\geq 25 \mathrm{~kg} / \mathrm{m}^{2}$ was prevalent in comparison group $(\mathrm{OR}=19.46 ; 95 \% \mathrm{Cl} 2.84-133.2 ; \chi 2$ $=15.4$, p 0.001). Alcohol abuse was considerably lower $-37.1 \%(n=52)$ $(\mathrm{OR}=54.72 ; 95 \% \mathrm{Cl} 17.87-167.44 ; \chi 2=88.8, \mathrm{p} \quad 0.001)$, but medication use was higher - diuretics in $16.4 \% \quad(n=23) \quad(O R=6.36 ; 95 \% \mathrm{Cl} 5.28-7.64$; $\mathrm{F}=0.045, \mathrm{p} 0.001)$ and low-dose aspirin in $35.0 \% \quad(\mathrm{n}=49)$ of patients $(\mathrm{OR}=17.41 ; 95 \% \mathrm{Cl} 14.80-20.47 ; \mathrm{F}=0.147, \mathrm{p} 0.001)$. In the study group, the urolithiasis was evidenced more often $(\mathrm{OR}=4.13 ; 95 \% \mathrm{Cl} 3.42-4.98 ; \chi 2$ $=12.1, \mathrm{p}$ 0.001), and the presence of CKD with GFR $60 \mathrm{ml} / \mathrm{min} /$ $1.73 \mathrm{~m}^{2}$ was observed in $15.0 \%(\mathrm{n}=21)$ of patients $(F=0.069, p 0.001)$, but not found in the comparison group. The percentage of patients with metabolic syndrome (3 components according to ATP III) did not differ between the groups ( $p$ 0.05).

The number of patients having a concentration of uric acid (UA) in blood

$360 \mathrm{mkmol} / \mathrm{l}$ and $480 \mathrm{mkmol} / \mathrm{l}$ was similar in the both study and comparison groups ( $p$ 0.05). At the same time, the cases of UA 600 $\mathrm{mkmol} / \mathrm{l}$ were higher in study group by $13.1 \%(\mathrm{OR}=1.86 ; 95 \% \mathrm{Cl} 1.50-2$ .38; $\chi 2=5.94, p=0.015$ )

Conclusion: Among our patients, the gout developing on the basis of pre-existing CVD is one of the variant of a debuting gout. The group of patients with so called "cardiovascular gout" is characterized by later gout onset, comorbidities typical for CVD, prevalence of medication (low-dose aspirin, diuretic) and renal mechanisms-triggers of gout. In these patients, the maximal concentration of UA in blood ( $600 \mathrm{mkmol} / \mathrm{l}$ ) was registered more frequently than in patients with primary gout.

Disclosure of Interests: None declared

DOI: 10.1136/annrheumdis-2019-eular.4363

\section{$\mathrm{AB} 0879$ \\ INTRATENDINOUS TOPHI IN PATIENTS WITH GOUT: PERSISTENCE IN SPITE OF CLINICAL CONTROL AND SCOPE OF URICEMIA THERAPEUTIC TARGET}

Carlos Guillén-Astete, Patricia Morán-Alvarez. Hospital Ramón Y Cajal, MADRID, Spain

Background: The tendon affectation of the gout consists of the deposit of uric acid in territories habitually perientésicos causing its accumulation in the substance of the body of the tendon or occupying part of it and protruding towards zones of extension. Their presence is usually not clinically accounted for except when they obstruct tendon displacement and therefore their role as part of the clinical picture of patients with gout is often underrepresented.

Objectives: The purpose of this study is to determine the ultrasound response of these tophi once the clinical activity has been controlled and the serum uricemia therapeutic target of $6.0 \mathrm{mg} / \mathrm{dL}$ has been reached. Methods: Quasi-experimental study type before after. We include 19 patients with tophaceous gout diagnosed between 2012 and 2014 and followed regularly in three rheumatology consultations through clinical, analytical and ultrasound controls. We compared the ultrasound records of static images of your Achilles, patellar and tricipital tendons at the time of diagnosis and in your last review. The longitudinal measurements of the tophi obtained were compared. The independent variable was the evaluation time (before and after) and the dependent variables were the quantification of tophi and their measurements in the longitudinal axis.

Results: All the patients were male. Mean age of 58 SD 6.8 years (Range 29-76). Mean basal uric acid $11.3 \mathrm{mg} / \mathrm{dL}$. Mean follow-up time to reach therapeutic objective 18 SD 10 months (Range 9-61). Median number of intratendinous tophi (counting one for each tendon of 6 possible tendons): 2. Fashion 2 (Range 1-4). Mean longitudinal diameters: Achilles (8 cases) 18.3 SD 4.2 mm; Rotulian (11 cases) 15.3 SD $3.1 \mathrm{~mm}$; Tricipital (6 cases) $9.8 \mathrm{SD} 5.1 \mathrm{~mm}$. Hypouricemiant treatment administered: Alopurinol 12; Alopurinol followed by Febuxostat 7; Febuxostat only 0. In the ultrasound study, once the therapeutic objective was reached, the accounting of the intratendinous tophi Achilles and patellar tophi remained identical. One tricipital tofo disappeared completely and the rest were maintained. The longitudinal measurements of tophi that did not disappear were as follows: Achilles 18.0 SD $3.2 \mathrm{~mm}(\mathrm{P}=0.805)$; Rotulian $14.9 \mathrm{SD}$ $3.2(\mathrm{P}=0.803)$; Tricipital $7.9 \mathrm{SD} 3.2(\mathrm{~N}=5, \mathrm{P}=0.489)$. No differences were detected when comparing the two hypouricemiant treatment sequences.

Conclusion: Although this is a small retrospective cohort, our results show a poor ultrasound response of reduction of intratendinous tophi reaching the serum uricemia target of $6.0 \mathrm{mg} / \mathrm{dL}$. This observation raises two reflections: (1) On the one hand, and as already proposed, the therapeutic target of uricemia in our patients could require an even stricter adjustment and (2) on the other hand, it would be necessary to consider whether the inclusion of regulated ultrasound scans of certain tendons would have clinical value if they were routinely incorporated into the study of our patients with gout.

\section{DISCLOSURE OF INTERESTS}

None declared

DOI: 10.1136/annrheumdis-2019-eular.8206

\section{AB0880 ACUTE GOUTY ARTHRITIS RELATED EMERGENCY DEPARTMENT VISITS AMONG US VETERANS: CHARACTERISTICS, PREDICTORS AND AREAS OF IMPROVEMENT}

Debendra Pattanaik, Zunaira Ali, Amado Freire. University of Tennessee Health Science Center, Memphis, United States of America

Background: Gout is quite prevalent among United States veterans and many do not achieve optimal levels of uric acid $(<6 \mathrm{mg} / \mathrm{dl}){ }^{1}$ This suggests that there are large number of veterans who are at risk for gout flare, leading to utilization of health care resources such as emergency department (ED) and outpatient office visits. We investigated the ED visit patterns among veterans with history of gout and the factors contributing to ED visits.

Objectives: The objectives of the study were to identify the risk factors for ED visits by veterans for gout flare up. Future remediation of the risk factors would reduce utilization of health care resources.

Methods: This was a retrospective chart review of veterans diagnosed with gout in the ED at VA Medical Center Memphis TN between January $1^{\text {st }}, 2011$ and December $31^{\text {st }}, 2016$ using ICD-9 codes. A rheumatologist reviewed all cases and only confirmed cases of gout were included in the study. There were 2516 veterans seen for acute gout during the 